\title{
In Search of Lost Trams: Comparing 1925 and 2020 Transit Isochrones in Sydney
}

\author{
Bahman Lahoorpoor ${ }^{1}$ (1) ${ }^{a}$, David Levinson ${ }^{1}$ (D) ${ }^{b}$ \\ ${ }^{1}$ School of Civil Engineering, University of Sydney \\ Keywords: Access, Public transit, Trams, Isochrones \\ https://doi.org/10.32866/001c.33040
}

\section{Findings}

Has Sydney lost access by removing its extensive tram network? We compare the 1925 tram network with today's bus network, and conclude that the access provided today exceeds what would have been provided by just trams. The Sydney CBD would have had better access if 1925 's central tram lines were still in operation.

\section{Questions}

Transport and land use have a long history of being intertwined, and access is a concept that reflects transport-land use interaction. Access provided by the transport network is one of the primary drivers of population dispersion in metropolitan areas (Acheampong and Silva 2015; Badoe and Miller 2000; Cordera et al. 2017; Hansen 1959; Levinson 2008; Lierop et al. 2017; Wegener 2021). Prior to automobilization, public transport (particularly trams and trains) was the primary mode of movement, and it significantly altered the structure and shape of many cities around the world.

In Sydney, the first steam train line opened in 1855 for passenger and freight service between Sydney and Parramatta (Sydney's second historical core and the colony's first seat of government), which at the time was a center of agriculture. The New South Wales Government Railway system was soon complemented by an extensive tram system, but the tram system was disrupted in the twentieth century by the rise of the automobile. Except limited decommissionings, Sydney Trains has grown since its birth.

In contrast, Sydney's tram experienced an entire lifecycle: born in 1879 with the first steam tram line in the City of Sydney (there was a single horse-drawn tram service during 1861-1866); reached its maximum extent (over $290 \mathrm{~km}$ ) around 1925; and was entirely removed by 1961 . Many of the tram lines were replaced by buses, and some segments were joined to the train network. In 1997, the tram network was reborn in the form of modern light rail (LRT), giving a second life to this mode of transport. The lifecycle of the Sydney transit networks and their ridership is depicted in Figure 1.

\footnotetext{
a Corresponding author:

bahman.lahoorpoor@sydney.edu.au

b david.levinson@sydney.edu.au
} 


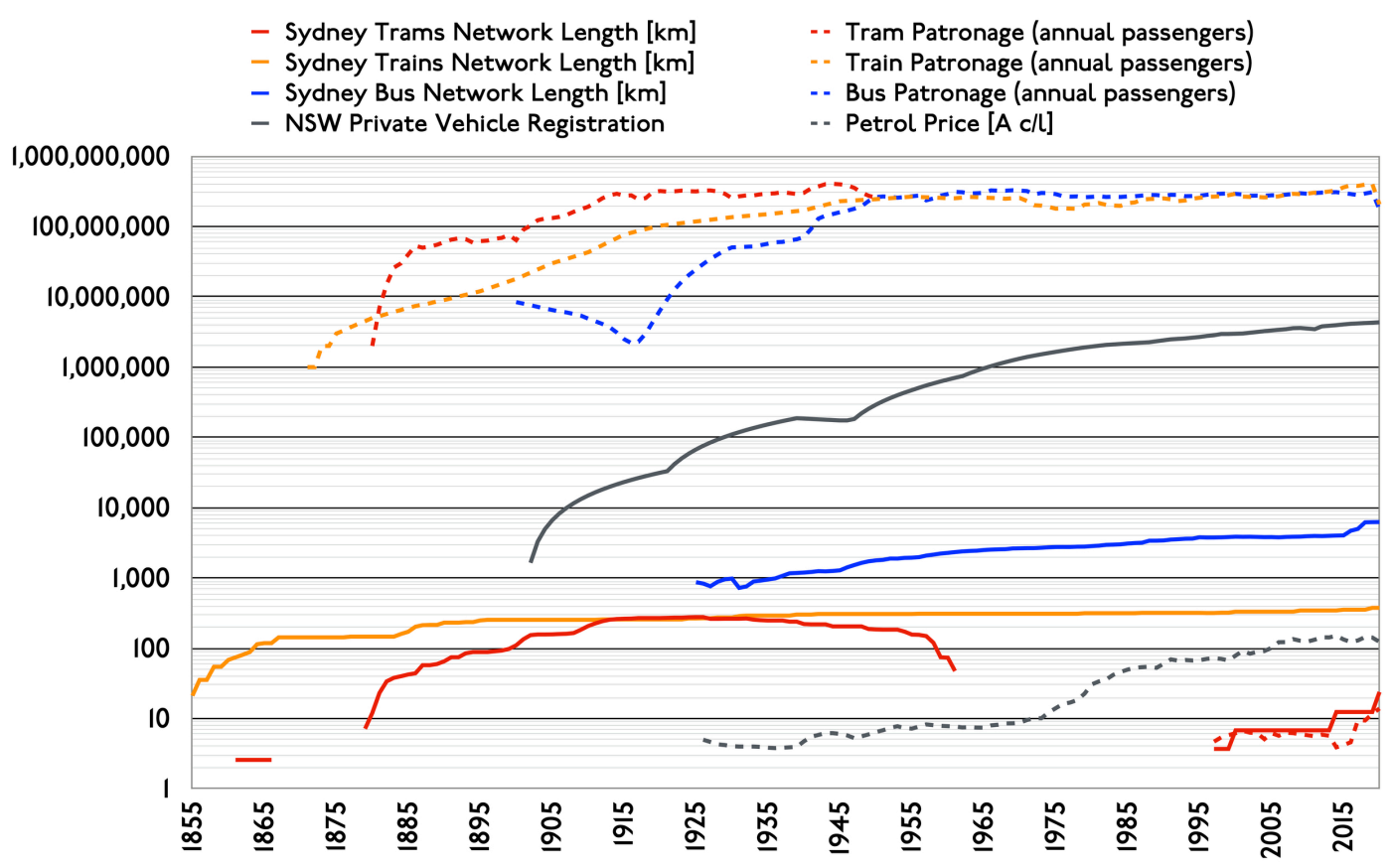

Figure 1. Lifecycle of the Sydney Transit networks (1855-2020)

Melbourne, which historically competes with Sydney for the title of the largest city in Australia, has maintained its tram network since 1889. There remains a dispute about whether Sydney should have kept its extensive tram network (Railpage 2012; Freestone 2004; Spearritt 2014; Ticher 2019).

The growth of transport networks has been well studied in the literature (Cats 2017; Doménech 2009; Feng and Chen 2010; Xie and Levinson 2009; Yang and Chen 2018). However, only a few studies have investigated the historical accessibility (Fuhrer 2020; Kasraian et al. 2016; Kim et al. 2021; Li et al. 2021; Tschopp, Fröhlich, and Axhausen 2005) due to the lack of historical records of transit schedules and services. Comparing historical access by different modes and different potential combinations has remained a research gap.

This study aims to find whether trams expanded accessibility relative to buses by comparing the services provided by historical trams, the replaced bus services, and the remaining train and light rail networks. We compare 1925, when the tram system was at its peak (just before the widespread operation of buses), and 2020.

\section{Methods}

In transport geography, isochrones illustrate the reachable space from a center within a travel time threshold. They can represent local access by one or a combination of transport modes, and they are graphically informative and easily understood by both transport analysts and non-experts. The accurate way to measure isochrone has been discussed in the literature (Lahoorpoor 
and Levinson 2020). This study uses the same methodology to calculate the isochrones from a point to compare access by historical transit systems and today's network.

Isochrones are drawn by drawing fixed buffers (50m diameter) around the service area from each tram stop and train station. The service area shows how far the land around a transit stop is accessible with a fixed travel time from a center of interest (Central Station). Equation 1 notes the service area distance from a stop mathematically.

$$
D_{i}=\left[T_{O}-t_{O, i}\right] \times V_{w}
$$

where $D_{i}$ is the service area distance from stop $i$; $T_{O}$ is the isochrone time threshold from the origin $O$ (e.g. 10, 20, 30, 40, 50, and 60 minutes); $t_{O, i}$ is the travel time between origin and stop $i$; and $V_{w}$ is the walking speed which is considered to be $4.8 \mathrm{~km} / \mathrm{h}$ (3 miles per hour). There is no maximum transfer and no transfer penalty is set.

In order to aggregate the access of all blocks in the study area (official census meshblocks), person-weighted access (PWA) is measured (Hansen 1959; Wu and Levinson 2020) as Equation 2.

$$
\begin{gathered}
A_{i, T}=\sum_{j=1}^{J} P_{j} f\left(C_{i j}\right) \\
f\left(C_{i j}\right)= \begin{cases}1 & \text { if } C_{i j} \leq T \\
0 & \text { otherwise }\end{cases} \\
A_{p w, T}=\frac{\sum\left(P_{i} \times A_{i, T}\right)}{\sum^{I} P_{i}} \quad \forall i: i \in I
\end{gathered}
$$

where cumulative opportunities of block $i$ in time $T$ is given by $A_{i, T}, P_{i}$ and $P_{j}$ is the population of block $i$ and $j, C_{i j}$ is the generalized travel cost (in terms of time) from region $i$ to region $j$, and $f\left(C_{i j}\right)$ is the impedance function. $A_{p w, T}$ aggregates the average person-weighted access (PWA) of all blocks in the area of study.

The location of tram stops and services of tram lines are collected from historical records (Keenan 1979). Historical transit schedules have been digitized into a standard format (GTFS) (Rayaprolu and Levinson 2021; Lahoorpoor and Levinson 2021, 2019). Where applicable, the tram and train average speeds are considered to be 20 and $30 \mathrm{~km} / \mathrm{h}$, respectively. The travel time is then calculated for one origin (Central Station) and many destinations (tram stops and other train stations), and also from all meshblocks to all meshblocks (for measuring PWA) by walk and transit, using OpenTripPlanner V1.3.0 (Pereira et al. 2019) which performs $A^{*}$ algorithm with a single variable 
generalized cost optimization. The single variable optimization does not guarantee the overall shortest travel time path (Peter 2017). For all scenarios, access to the population is measured using data from the 2016 census.

To compare access between 1925 and 2020, six scenarios are defined:

- Scenario 1 shows the access by trams and trains in 1925.

- Scenario 2 shows the 2020's access by transit.

- Scenario 3 reflects the effect of 1925 's train on access.

- Scenario 4 relates to 2020's access if no buses were in place, which shows the effect of buses on access compared to scenario 2.

- Scenario 5 is the case where the 1925 's trams are still operating without being replaced by buses.

- Scenario 6 is an ideal situation as if the 1925 trams still existed with respect to all other network developments.

\section{Findings}

Figures $\underline{2 a}$ and $\underline{2 b}$ illustrate the isochrones for the first and second scenarios. They show the travel time from Sydney Central Station at six thresholds (10 minutes intervals) for 1925's trams and train stops (fixed points). The first scenario is when only Sydney trams and trains were operating in 1925. The tram system extended access towards the south and eastern suburbs, while trains expanded access to the west. Comparing the isochrones with the second scenario (2020), Central Station is more accessible in almost all-time thresholds than in 1925 . The reason is that more frequent and faster transit services are available. Also, the expanded train network has reduced the travel time to the outer suburbs.

The maps cannot fully answer the question though, as other things have changed as well. Access to population for six time thresholds is measured as shown in Figure 3. Results indicate that except for 10-minute travel time, the access provided today exceeds what would have been provided by just trams. Still given all the developments in other modes of transport, if 1925 trams had not been replaced by 2020 buses, the network would have provided higher PWA and higher access to Central Station for trips longer than 40 minutes. It is worth noting that in terms of PWA, scenario S1 is better than S2 for travel up to 30 minutes.

In order to quantify the changes between scenarios, the difference of covered area and the number of people that fall into those boundaries are measured as illustrated in Table 1. Results indicate that today's public transport has improved the 20-40 minutes bracket of access to Central since 1925. However, shorter or longer travel times are not significantly changed. 


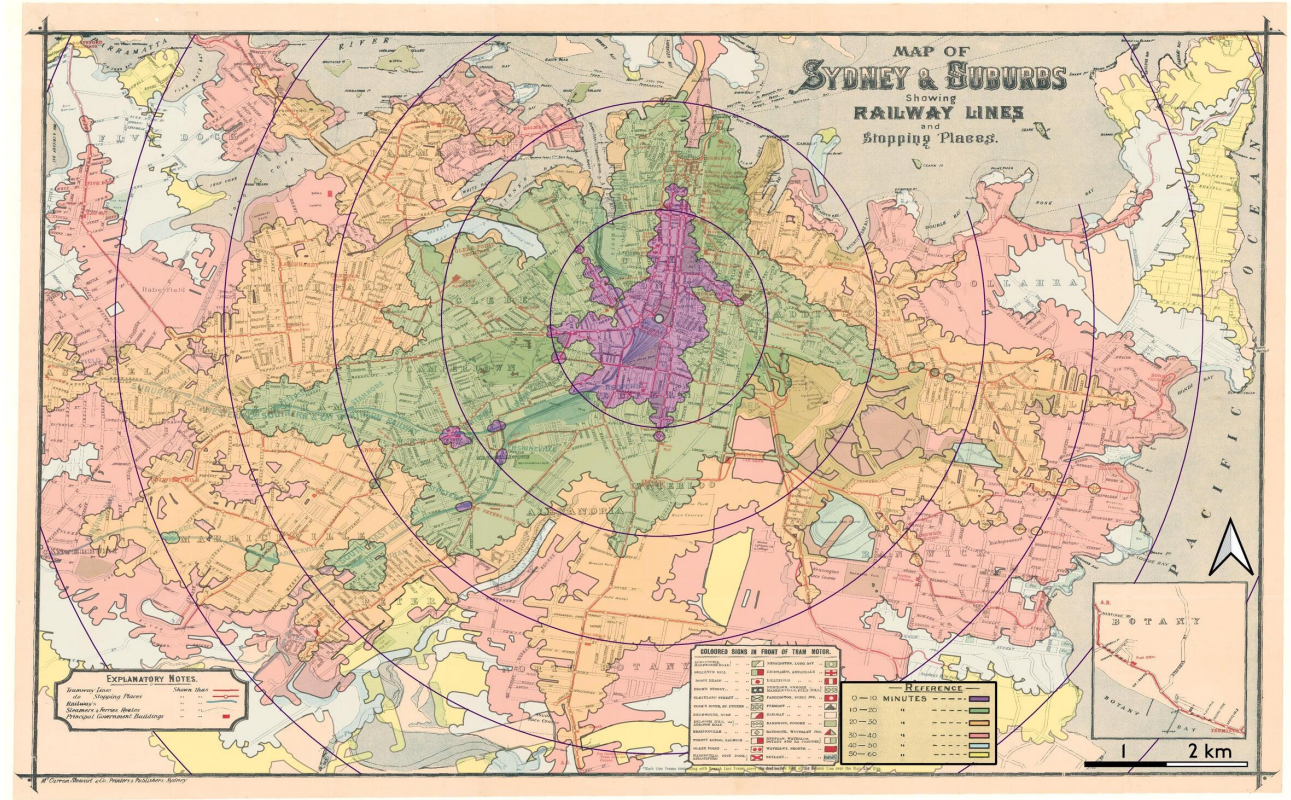

Figure 2a. 1925 Trams \& Trains (Scenario 1)

Basemap: McCarron Stewart \& Co. (1907)

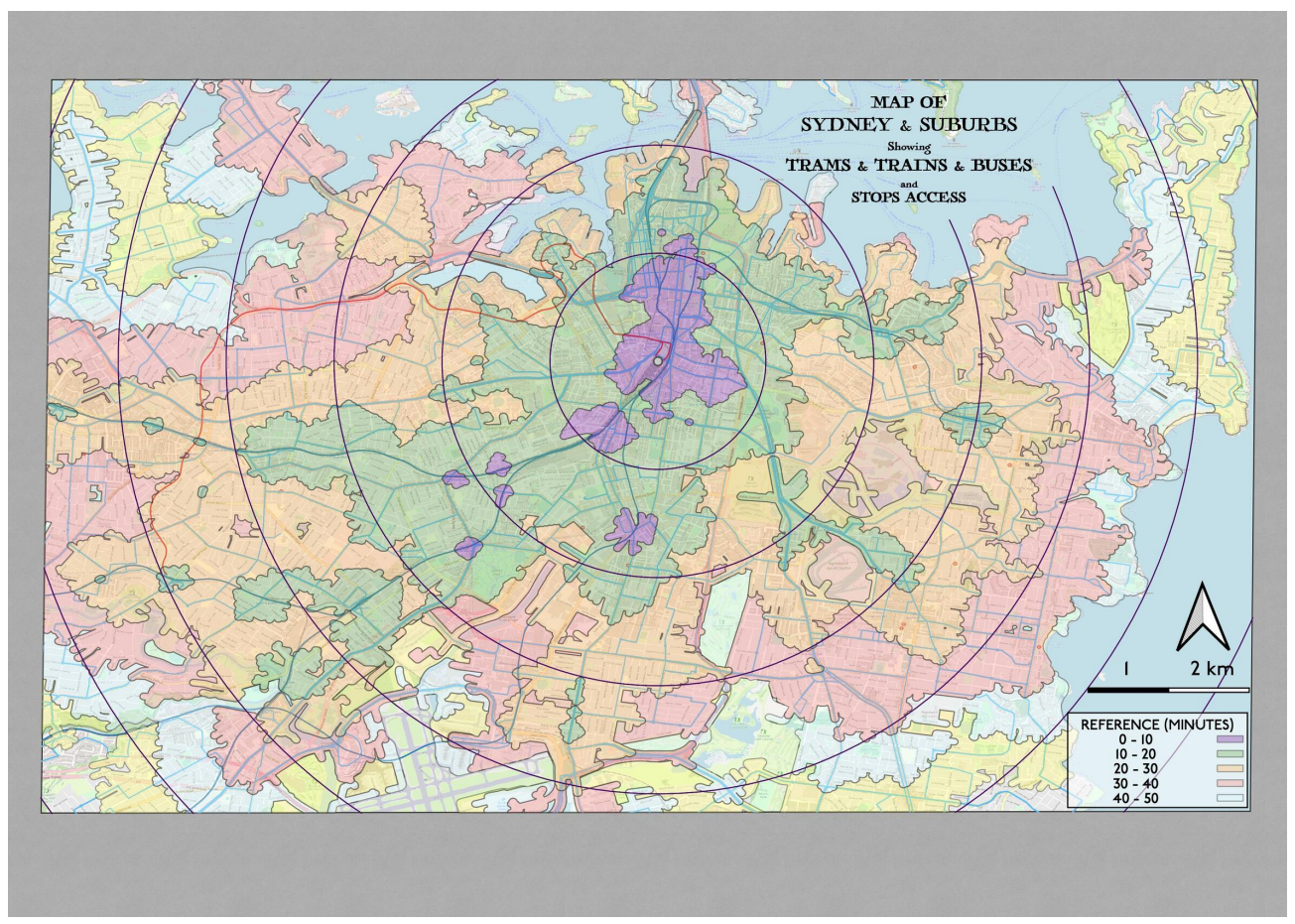

Figure 2b. 2020 Transit (Scenario 2)

Basemap: OpenStreetMap.

Comparing the effects of trams and buses (as in Table 2), it is evident that trams had a remarkable effect on access, and the role of buses is lower. However, with the extended train line to the eastern suburbs, buses compensate for the 


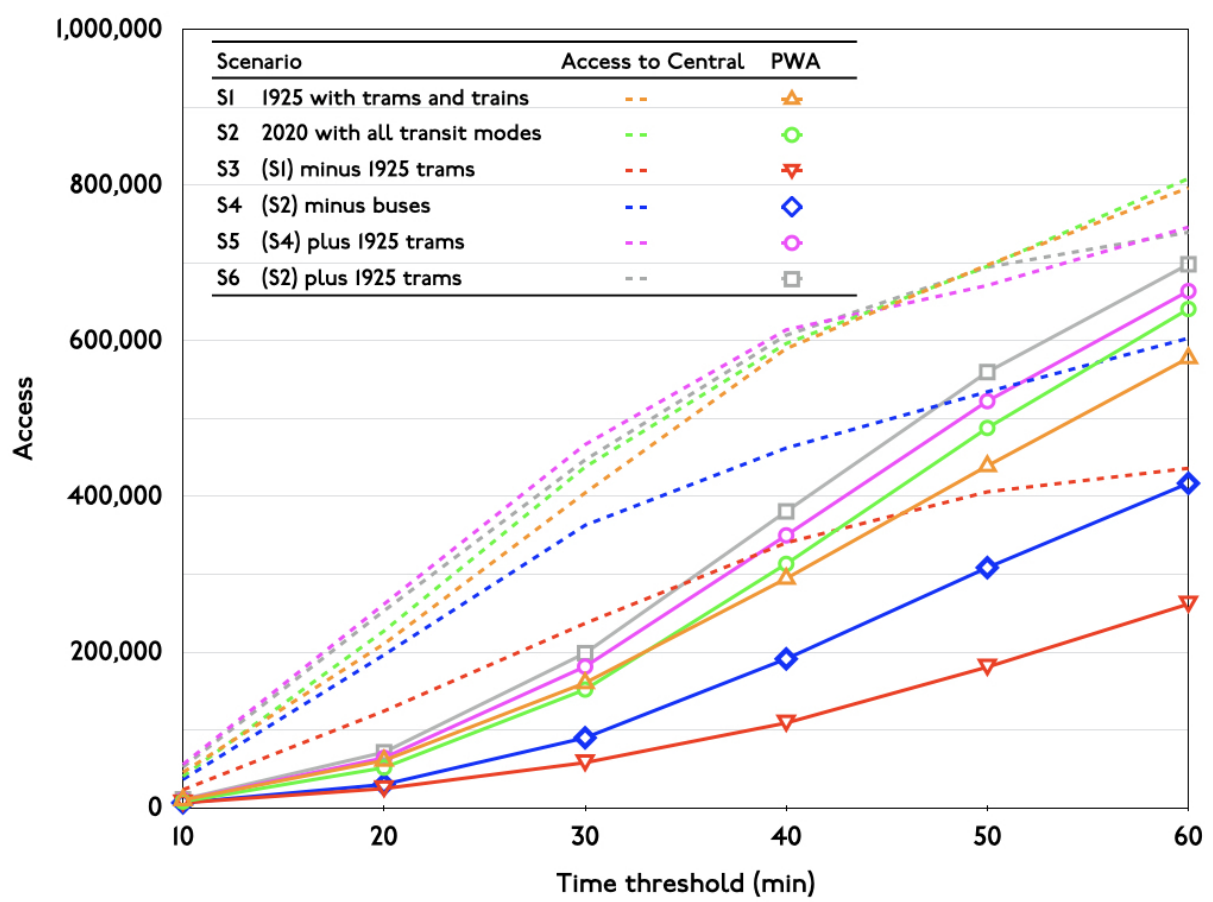

Figure 3. Access to population and person-weighted access (PWA) for each scenario

lost tram services due to the integral effect of public transit. It is worth noting that shorter travel times are not affected due to the circuity of bus services. However, the 0-30 minutes bracket could have been improved by 1925 trams ( $S 5$ minus $\mathrm{S1}$ ) if they remained in operation (at least in the $\mathrm{CBD}$ ).

The results for the comprehensive scenario S6 (2020 plus 1925 trams) illustrate the highest PWA and the highest access to Central Station for 0-40 minutes travel times, whereas for higher time thresholds, S6 has lower access than scenario S2 (2020 only). This is because the $A^{*}$ heuristic algorithm selects the fastest intermediate segments (which may have higher transfer times) when finding the shortest path from an origin due to single generalized cost optimization.

This paper concludes that, from an accessibility perspective, replacing trams with buses has not generally lessened access to the Sydney CBD. Instead, with more bus routes, the mid-range access has been expanded to the outskirts of the city. Clearly, there are combinations of today's buses and yesterday's trams, or other imagined but not provided services, that provide a higher level of access than an either/or approach. Different time thresholds have an impact on the interpretability of access measurements, as well as the extent to which such measures may explain travel mode choice (Xi, Miller, and Saxe 2018). The correlation between ridership and access to population or jobs in Sydney needs more study. Other urban aesthetic aspects, questions of ride quality, and issues about perception of travel service when comparing buses with restoring past tram services need further investigation. 
Table 1. Differences of scenarios: Access to Central Station

\begin{tabular}{|c|c|c|c|c|c|c|c|}
\hline \multirow[b]{2}{*}{$\begin{array}{l}\text { Time } \\
\text { [min] }\end{array}$} & \multirow[b]{2}{*}{ Difference } & \multicolumn{2}{|c|}{ (a) S2 - S1 } & \multicolumn{2}{|c|}{ (b) S4 - S1 } & \multicolumn{2}{|c|}{ (c) S5 - S1 } \\
\hline & & $\begin{array}{c}\text { Area } \\
{\left[\mathrm{km}^{2}\right]}\end{array}$ & Persons & $\begin{array}{c}\text { Area } \\
{\left[\mathrm{km}^{2}\right]}\end{array}$ & Persons & $\begin{array}{c}\text { Area } \\
{\left[\mathrm{km}^{2}\right]}\end{array}$ & Persons \\
\hline \multirow{3}{*}{$0-10$} & Added & 1.2 & 10,208 & 0.8 & 6,725 & 0.8 & 6,820 \\
\hline & Lost & 1.3 & 15,360 & 1.3 & 15,804 & 0.1 & 223 \\
\hline & Balance & -0.1 & $-5,152$ & -0.5 & $-9,079$ & 0.7 & 6,597 \\
\hline \multirow{3}{*}{$10-20$} & Added & 7.7 & 53,068 & 4.8 & 38,093 & 5.8 & 42,849 \\
\hline & Lost & 4.6 & 36,410 & 6.9 & 52,167 & 0.1 & 244 \\
\hline & Balance & 3.1 & 16,658 & -2.1 & $-14,074$ & 5.7 & 42,605 \\
\hline \multirow{3}{*}{$20-30$} & Added & 12.3 & 61,452 & 6.8 & 33,889 & 9.2 & 42,373 \\
\hline & Lost & 5.5 & 28,247 & 13.2 & 75,527 & 0 & 0 \\
\hline & Balance & 6.8 & 33,205 & -6.4 & $-41,638$ & 9.2 & 42,373 \\
\hline \multirow{3}{*}{$30-40$} & Added & 7.5 & 26,097 & 3.5 & 13,817 & 7.5 & 30,623 \\
\hline & Lost & 4.8 & 19,646 & 24.9 & 141,636 & 2.4 & 13,506 \\
\hline & Balance & 2.7 & 6,451 & -21.4 & $-127,819$ & 5.1 & 17,117 \\
\hline \multirow{3}{*}{$40-50$} & Added & 6.9 & 24,408 & 2.7 & 10,088 & 6.1 & 23,934 \\
\hline & Lost & 5.3 & 26,145 & 33.9 & 173,015 & 6.2 & 26,673 \\
\hline & Balance & 1.6 & $-1,737$ & -31.2 & $-162,927$ & -0.1 & $-2,739$ \\
\hline \multirow{3}{*}{$50-60$} & Added & 8.2 & 22,627 & 2.6 & 5,801 & 5.3 & 10,790 \\
\hline & Lost & 2.2 & 10,671 & 43.9 & 199,025 & 13.7 & 67,917 \\
\hline & Balance & 6.0 & 11,956 & -41.3 & $-193,224$ & -8.4 & $-57,127$ \\
\hline
\end{tabular}

Notes:

a) between 2020 with all modes (S2) and 1925 trams plus trains (S1);

b) between 2020 minus buses (S4) and 1925 trams plus trains (S1);

c) between 2020 all modes minus buses plus 1925 trams (S5) and 1925 trams plus trains (S1)

Table 2. Added access by buses in 2020 and by trams in 1925

\begin{tabular}{|c|c|c|c|c|c|c|}
\hline \multirow[b]{2}{*}{$\begin{array}{l}\text { Time } \\
\text { [min] }\end{array}$} & \multicolumn{3}{|c|}{ Buses in 2020 (S2 - S4) } & \multicolumn{3}{|c|}{ Trams in 1925 (S1 - S3) } \\
\hline & $\begin{array}{c}\text { Area } \\
{\left[\mathrm{km}^{2}\right]}\end{array}$ & Persons & PWA & $\begin{array}{l}\text { Area } \\
{\left[\mathrm{km}^{2}\right]}\end{array}$ & Persons & PWA \\
\hline $0-10$ & 0.4 & 3,927 & 1,485 & 2.0 & 22,413 & 3,693 \\
\hline $10-20$ & 5.2 & 30,732 & 21,594 & 12.3 & 86,245 & 36,151 \\
\hline $20-30$ & 13.3 & 74,843 & 61,988 & 27.0 & 167,637 & 102,414 \\
\hline $30-40$ & 24.2 & 134,270 & 122,054 & 46.5 & 249,558 & 185,641 \\
\hline $40-50$ & 32.9 & 161,190 & 179,451 & 57.6 & 291,487 & 258,444 \\
\hline $50-60$ & 47.3 & 205,180 & 223,962 & 71.4 & 360,315 & 316,213 \\
\hline
\end{tabular}

Submitted: November 03, 2021 AEDT, Accepted: February 23, 2022 AEDT 
This is an open-access article distributed under the terms of the Creative Commons Attribution 4.0 International License (CCBY-SA-4.0). View this license's legal deed at https://creativecommons.org/ licenses/by-sa/4.0 and legal code at https://creativecommons.org/licenses/by-sa/4.0/legalcode for more information. 


\section{REFERENCES}

Acheampong, Ransford A, and Elisabete A Silva. 2015. "Land Use-Transport Interaction Modeling: A Review of the Literature and Future Research Directions." Journal of Transport and Land Use 8 (3): 11-38.

Badoe, Daniel A, and Eric J Miller. 2000. "Transportation-Land-Use Interaction: Empirical Findings in North America, and Their Implications for Modeling." Transportation Research Part D: Transport and Environment 5 (4): 235-63.

Cats, Oded. 2017. "Topological Evolution of a Metropolitan Rail Transport Network: The Case of Stockholm." Journal of Transport Geography 62: 172-83.

Cordera, Rubén, Ángel Ibeas, Luigi dell'Olio, and Borja Alonso. 2017. Land Use-Transport Interaction Models. CRC Press.

Doménech, Antonio. 2009. "A Topological Phase Transition between Small-Worlds and Fractal Scaling in Urban Railway Transportation Networks?” Physica A: Statistical Mechanics and Its Applications 388 (21): 4658-68.

Feng, Jian, and Yanguang Chen. 2010. "Spatiotemporal Evolution of Urban Form and Land-Use Structure in Hangzhou, China: Evidence from Fractals." Environment and Planning B: Planning and Design 37 (5): 838-56. https://doi.org/10.1068/b35078.

Freestone, Robert. 2004. "The Americanization of Australian Planning." Journal of Planning History $3(3): 187-214$.

Fuhrer, Raphaël. 2020. "Modelling Historical Accessibility and Its Effects in Space.” PhD thesis, ETH Zurich.

Hansen, Walter G. 1959. "How Accessibility Shapes Land Use." Journal of the American Institute of Planners 25 (2): 73-76.

Kasraian, Dena, Kees Maat, Dominic Stead, and Bert Wee. 2016. "Long-Term Impacts of Transport Infrastructure Networks on Land-Use Change: An International Review of Empirical Studies." Transport Reviews 36 (6): 772-92.

Keenan, David R. 1979. Tramways of Sydney. Transit Press Sydney. https://nla.gov.au/nla.catvn2827955.

Kim, Youngjoon, Jinhyung Lee, Junghwan Kim, and Naoto Nakajima. 2021. "The Disparity in Transit Travel Time between Koreans and Japanese in 1930s Colonial Seoul.” Findings. https://doi.org/10.32866/001c.25226.

Lahoorpoor, Bahman, and David M Levinson. 2019. "The Transit Travel Time Machine: Comparing Three Different Tools for Travel Time Estimation.”

- - . 2020. "Catchment If You Can: The Effect of Station Entrance and Exit Locations on Accessibility.” Journal of Transport Geography 82: 102556.

- - . 2021. "An Empirical Model of Land Use and Public Transit Co-Developments in Sydney." Working Paper 06. The University of Sydney.

Levinson, David. 2008. "Density and Dispersion: The Co-Development of Land Use and Rail in London.” Journal of Economic Geography 8 (1): 55-77.

Li, Wenlong, Jan-Dirk Schmöcker, Ali-gul Qureshi, and Liang Zhao. 2021. “Historical Transportation Accessibility of Chinese Sui-Tang Period and Its Socioeconomics Influence.” In Proceedings of the Eastern Asia Society for Transportation Studies. Vol. 13.

Lierop, Dea, Geneviève Boisjoly, Emily Grisé, and Ahmed El-Geneidy. 2017. "Evolution in Land Use and Transportation Research.” In Planning Knowledge and Research, 130-51. Routledge. 
McCarron Stewart \& Co. 1907. Map of Sydney E'Suburbs Showing Tramway Lines and Stopping Places. http://nla.gov.au/nla.obj-229847778.

Pereira, R H M, L Grégoire, N Wessel, and J Martins. 2019. “"Tutorial with Reproducible Example to Estimate a Travel Time Matrix Using Open TripPlanner and Python.” https://doi.org/10.5281/ zenodo.324213.

Peter, Sebastian. 2017. "Multi-Modal Route Planning with Dynamic Public Transport Delays."

Railpage. 2012. "What If The Sydney Tram Network Wasn't Dismantled?” Online forum. 2012. https://www.railpage.com.au/f-p1650315.htm.

Rayaprolu, Hema, and David M Levinson. 2021. "Evolution of Sydney’s Bus Network: 1925 to 2020.” Working Paper 10. The University of Sydney.

Spearritt, Peter. 2014. "Why Melbourne Kept Its Trams.” In UHPH 14: Landscapes and Ecologies of Urban and Planning History, Proceedings of the 12th Conference of the Australasian Urban History/ Planning History Group. UHPHG and Victoria University Wellington.

Ticher, Mike. 2019. "Erased from History: How Sydney Destroyed Its Trams for Love of the Car." The Guardian, July. https://www.theguardian.com/australia-news/2019/jul/28/erased-fromhistory-how-sydney-destroyed-its-trams-for-love-of-the-car.

Tschopp, Martin, PH Fröhlich, and Kay W Axhausen. 2005. "Accessibility and Spatial Development in Switzerland During the Last 50 Years.” In Access to Destinations. Emerald Group Publishing Limited.

Wegener, Michael. 2021. "Land-Use Transport Interaction Models." Handbook of Regional Science, 229-46.

Wu, Hao, and David Levinson. 2020. "Unifying Access." Transportation Research Part D: Transport and Environment 83: 102355.

Xi, Yang, Eric J Miller, and Shoshanna Saxe. 2018. "Exploring the Impact of Different Cut-off Times on Isochrone Measurements of Accessibility.” Transportation Research Record 2672 (49): 113-24.

Xie, Feng, and David Levinson. 2009. “Topological Evolution of Surface Transportation Networks.” Computers, Environment and Urban Systems 33 (3): 211-23.

Yang, Zhijie, and Xiaolong Chen. 2018. "Evolution Assessment of Shanghai Urban Rail Transit Network.” Physica A: Statistical Mechanics and Its Applications 503: 1263-74. 